\title{
$\mathrm{MA}+\mathrm{SNMP}$ 기반의 계층적인 네트워크 관리구조
}

\author{
나 호 진 ${ }^{*}$, 조 경 산 ${ }^{* *}$
}

\section{Hierarchical network management based on MA+SNMP}

\author{
Ho-Jin $\mathrm{Na}^{*}$, Kyungsan Cho ${ }^{* *}$
}

\section{요 약}

효율적인 네트워크 관리를 위해 중앙 집중적인 구조, 분산 관리 구조, 그리고 하이브리드 구조와 같은 다양한 관 리 구조들이 연구되었지만, 어느 구조도 모든 환경에서 효율적이지는 못하다. 본 연구에서는 향후 활용이 많을 것으 로 기대되는 광범위한 영역에 분포된 많은 수의 저용량 $\mathrm{NE}$ (Network Element)들을 유연성 있게 관리하기 위한 $\mathrm{MA}+\mathrm{SNMP}$ 기반의 계층적 관리 구조를 제안한다. 제안 구조는 중간 관리 노드를 사용한 계층적 분할 관리 구조이 며 관리의 유연성과 $\mathrm{NMS}$ 의 부하 감소를 위하여 중간 관리 노드는 $\mathrm{MA}$ 기반의 분산 처리를 수행하고, $\mathrm{NE}$ 의 소규 모 특성을 고려하여 $\mathrm{NE}$ 는 $\mathrm{SNMP}$ 기반으로 동작한다. 분석을 통해 제시된 환경에서 제안 구조가 기존 관리 구조의 취약점을 해결하여 처리 시간이 개선됨을 보인다.

\begin{abstract}
Although various network management architectures such as centralized, distributed, and hybrid have been presented, any one is not always efficient in all the environment. In this paper, we propose a hierarchical and split network management architecture based on MA+SNMP in order to manage a network of many small NEs distributed over the wide area. Our hierarchical architecture has MA-based proxy management nodes for the flexibility and overhead reduction in NMS as well as SNMP-based NEs considering $\mathrm{NE}^{\prime}$ s capacity. Through the analysis with real experiments, we show that our proposal improves some drawbacks and the processing delay of the existing architectures in the given environment.
\end{abstract}

- Keyword : 네트워크 관리(Network Management), 이동 에이전트(Mobile Agent), SNMP(Simple Network Management Protocol), 성능 개선(Performance Improvement)

- 제1저자 : 나호진 교신저자 : 조경산

- 투고일 : 2010. 03. 19, 심사일 : 2010. 03. 30, 게재확정일 : 2010. 04. 06.

* 단국대학교 컴퓨터과학과 박사과정 ** 단국대학교 컴퓨터학부 교수

※ 이 연구는 2008년도 단국대학교 대학원 연구 보조 장학금의 지원으로 이루어진 것임. 


\section{I. 서 론}

다양한 네트워크 장비들이 등장하고 네트워크 규모가 거대 해 짐에 따라 효율적인 관리가 필요해졌고, 중앙 집중 구조, 분산 처리 구조, 하이브리드(Hybrid) 구조와 같은 다양한 네트워크 관리 구조가 제시되어왔다.

네트워크 관리를 위해 SNMP(Simple Network Management Protocol)가 가장 널리 사용되고 있지만, NMS(Network Manag ement System)가 중앙 집중적으로 $\mathrm{NE}$ (Network Element)들을 관리하기 때문에 $\mathrm{NMS}$ 의 과부하와 네트워크 트래픽의 병목 현상 그 리고 네트워크 전송 지연의 문제를 갖는다[1][2].

관리 프로그램 자체를 전송하여 다양한 관리와 분산 처리 가 가능한 MA(Mobile Agent) 기법을 적용한 네트워크 관 리 기법이 출연하여 SNMP 기반의 중앙 집중 구조의 문제점 이 개선되고 유연성과 확장성도 향상되었다[3]. 그러나 모든 $\mathrm{NE}$ 에 $\mathrm{MA}$ 플랫폼이 설치되어야하며 $\mathrm{MA}$ 의 전송에 따른 지 연의 문제점이 있다[4].

다양한 NE를 관리할 수 있도록 $\mathrm{SNMP}$ 기반과 MA 기반 의 $\mathrm{NE}$ 들이 혼합된 환경에 적용되는 하이브리드 네트워크 관 리 구조가 제안되었다[5]. 또한 중간 관리 노드를 갖는 계층 적 관리 구조와 $\mathrm{NE}$ 들을 분할하여 관리하는 분할 관리 구조도 제안되었다. 그러나 이들은 관리의 복잡성을 증가시키고 $\mathrm{NE}$ 들의 분포에 따라 성능이 유동적이라는 단점이 있다[6][7].

본 연구에서는 기존의 다양한 관리 구조의 특성을 분석하 여 많은 수의 소규모 NE들이 광범위한 영역에 분포되어 있는 환경에서 효율적인 $\mathrm{MA}+\mathrm{SNMP}$ 기반의 계층적 네트워크 관 리 구조를 제안한다. 제안 구조는 SNMP 기반의 중앙 집중 적인 네트워크 관리 문제점을 개선하기 위해 단일 $\mathrm{NMS}$ 에 의 한 중앙 집중 처리가 아닌 중간 관리 노드를 통한 $\mathrm{MA}$ 기반의 분산 처리로 동작하며, $\mathrm{MA}$ 기반의 분산 네트워크 관리의 단 점을 극복하기 위해 모든 소규모 $\mathrm{NE}$ 들은 $\mathrm{SNMP}$ 기반으로 동작하는 계층적 구조이다.

제안 구조는 NE들을 서브네트워크로 분할하여 관리하는 계층적 구조를 갖는다. 그리고 중간 관리 노드를 통한 $\mathrm{MA}$ 기 반의 분산 처리로 $\mathrm{NMS}$ 의 과부하와 네트워크 트래픽의 병목 현상을 개선하고, 소규모 $\mathrm{NE}$ 들은 $\mathrm{SNMP}$ 로 동작하게 하여 기존 네트워크 관리 구조보다 성능이 개선되었다.

본 논문은 다음과 같이 구성된다. 2장에서는 기존 네트워 크 관리 구조인 SNMP 기반의 중앙 집중적 네트워크 관리 구 조와 MA 기반의 네트워크 관리 구조 그리고 하이브리드 네 트워크 관리 구조를 분석하고, 3 장에서는 제시된 환경에 적합 한 네트워크 구조의 요구 사항과 본 연구에서 제안한 $\mathrm{MA}+\mathrm{SNMP}$
기반의 계층적인 네트워크 관리 구조에 대해 서술한다. 4장에 서는 3 장에서 제안한 $\mathrm{MA}+\mathrm{SNMP}$ 기반의 계층적인 네트워 크 관리 구조를 검증하고 기존 네트워크 관리 기법보다 성능 이 우수함을 보인다. 5장에서는 결론 및 향후 연구 방향에 대 해 기술한다.

\section{II. 기존 네트워크 관리 구조}

본 장에서는 기존의 다양한 네트워크 관리 기법을 $\mathrm{SNMP}$ 기반 관리, $\mathrm{MA}$ 기반 관리 그리고 하이브리드 관리의 세 가지 관리 구조로 분류하여 분석한다.

\subsection{SNMP 기반의 중앙 집중적 관리 구조}

$\mathrm{SNMP}$ 는 NMS가 NE로부터 직접 정보를 수집하여 네트 워크 관리를 수행하는 프로토콜이다.

네트워크 관리를 위해 가장 널리 사용되는 SNMP 네트워 크 관리 구조는 그림1과 같이 $\mathrm{NE}$ 를 감시하고 관리하는 $\mathrm{NMS}, \mathrm{NE}$ 에 자원 정보를 제공하기 위한 $\mathrm{SA}$ (SNMP Agent), $\mathrm{NMS}$ 와 $\mathrm{SA}$ 사이에 관리 대상 객체를 정의한 $\mathrm{MB}$ (Management Information Base) 그리고 NMS와 SA 사이의 통신 프로토 콜인 SNMP로 구성된다[1][8].

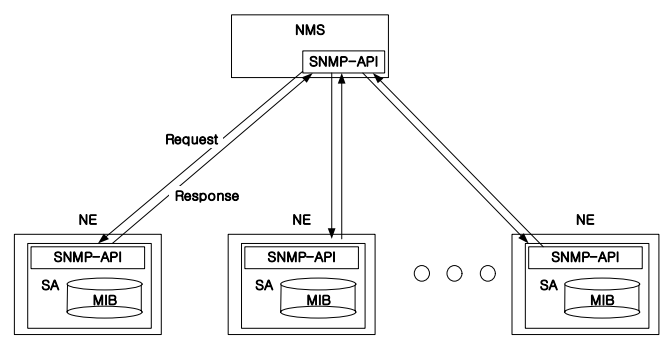

그림 1. SNMP 기반의 네트워크 관리구조

Fig. 1. Network management architecture based on SNMP

$\mathrm{SNMP}$ 기반 구조에서는 NMS가 각 $\mathrm{NE}$ 에 있는 $\mathrm{SA}$ 에게 $\mathrm{SNMP}$ 프로토콜로 정보를 요청하고 $\mathrm{SA}$ 는 $\mathrm{MIB}$ 정의를 기반 으로 NMS에게 응답한다.

표준화된 네트워크 관리 프로토콜인 $\mathrm{SNMP}$ 는 기능과 특 성이 개선되면서 첫 버전인 $\mathrm{SNMPv} 1$ 에서 $\mathrm{SNMPv2}$ 와 $\mathrm{SNMPv} 3$ 로 확장되었다. $\mathrm{SNMPv} 1$ 은 $\mathrm{NMS}$ 가 $\mathrm{SA}$ 의 객체 값을 검색하 는 SNMP-Get과 SNMP-GetNext, NMS가 SA의 객체 값 을 설정하는 $\mathrm{SNMP}-\mathrm{Set}$, 그리고 $\mathrm{SA}$ 의 이벤트를 $\mathrm{NMS}$ 에게 알리기 위한 SNMP-Trap을 통해 동작한다. 테이블 형태로 $\mathrm{SA}$ 에 존재하는 많은 객체 정보의 값을 읽으려면, 많은 요청 
과 응답 메시지를 반복해야 하는 SNMPv1의 문제점을 극복 하기 위해 하나의 메시지가 허용하는 크기까지 여러 객체들의 값을 읽어 올 수 있는 SNMP-GetBulk 기능이 다음 버전인 $\mathrm{SNMPv} 2$ 에 추가 되었다. 그리고 $\mathrm{SNMP}$ 의 보안 문제를 해 결하기 위해 SNMPv3가 도입되었다.

$\mathrm{NMS}$ 는 SNMP 메시지를 통해 SA로부터 주기적으로 데이 터를 수집하여 중앙에서 모든 $\mathrm{NE}$ 들을 관리 할 수 있다는 장점 이 있다. 하지만, 모든 요청과 응답이 $\mathrm{NMS}$ 에 집중되어 있기 때문에 $\mathrm{NMS}$ 에 과부하가 발생하고 네트워크 트래픽의 병목 현상이 발생하는 단점이 있다[9]. 그러므로 이 구조는 작은 영 역에 분포되어 있는 소수의 소규모 $\mathrm{NE}$ 의 관리에 적합하다.

\subsection{MA 기반의 네트워크 관리 구조}

$\mathrm{MA}$ 는 프로그램이 데이터와 함께 다른 호스트로 이동하여 원하는 작업을 수행하고 다른 이동 에이전트들과 통신할 수 있는 특별한 소프트웨어이다[10].

기존의 $\mathrm{SNMP}$ 기반의 중앙 집중적인 네트워크 관리의 제약 을 극복하기 위해서 $\mathrm{MA}$ 기법을 네트워크 관리에 적용하여, 관 리의 유연성과 분산 처리를 제공하는 $\mathrm{MA}$ 기반의 네트워크 관 리 기법이 제시되었다. 네트워크 관리를 위한 MA는 $\mathrm{NMS}$ 에서 $\mathrm{NE}$ 를 통해 다른 $\mathrm{NE}$ 들에게 이동되므로 $\mathrm{NMS}$ 에서의 네트워크 부하와 트래픽을 줄이고, 대부분의 전송 및 이동은 지역 네트워 크에서 이루어지므로 네트워크 지연 시간을 줄일 수 있다[11].

$\mathrm{MA}$ 기반의 네트워크 관리 구조는 $\mathrm{NMS}$ 와 $\mathrm{SA}$ 그리고 ASDK(Aglets Software Development Kit)로 구성된다 〔12]. ASDK는 자바 기반의 $\mathrm{MA}$ 개발 환경 및 실행 환경으로 aglet, aglet context, proxy 그리고 message로 구성된다. aglet은 직렬화 된 자바 객체로 네트워크를 통해 다른 호스트 로 이동하여 실행되는 객체이고, aglet context는 aglet이 실 행될 수 있는 환경을 제공하고, proxy는 aglet의 대리인 역할 을 하여 aglet의 실제 위치가 노출되지 않도록 aglet의 위치에 대한 투명성을 제공한다. 그리고 message는 다른 aglet과 통 신을 할 때 메시지를 전송하기 위해 제공된다. $\mathrm{NMS}$ 에 존재하 는 $\mathrm{ASDK}$ 는 $\mathrm{MA}$ 인 aglet를 $\mathrm{NE}$ 상의 $\mathrm{ASDK}$ 로 이동시키고, 이 동된 MA는 필요한 정보를 수집하거나 설정한다[13].

$\mathrm{NMS}$ 에서 $\mathrm{MA}$ 기반으로 네트워크를 관리하는 방법으로 $\mathrm{GnG}$ (Get 'n' Go)와 $\mathrm{GnS}$ (Go 'n' Stay)이 제시되었고, 또한 이들을 수정한 $\mathrm{DnD}(\mathrm{Do}$ 'n' Die) 가 제안되었다[4][14].

그림2에 보인 $\mathrm{GnG}$ 관리는 다음의 순서로 동작한다.

1) $\mathrm{MNS}$ 의 $\mathrm{ASDK}$ 가 MA를 생성한다.

2) 생성된 MA는 하나의 NE로 이동한다.

3) $\mathrm{NE}$ 에 도착한 $\mathrm{MA}$ 는 동일 호스트에 존재하는 $\mathrm{SA}$ 와 요
청과 응답을 통해 작업을 수행하고 수행 결과와 상태를 저장한다.

4) MA는 선정된 경로를 따라 다른 $\mathrm{NE}$ 로 이동하여 3)을 반복하여 수행한다,

5) MA가 마지막 NE에 도착해서 수행을 마치면, 수집된 데이터와 함께 NMS로 되돌아간다.

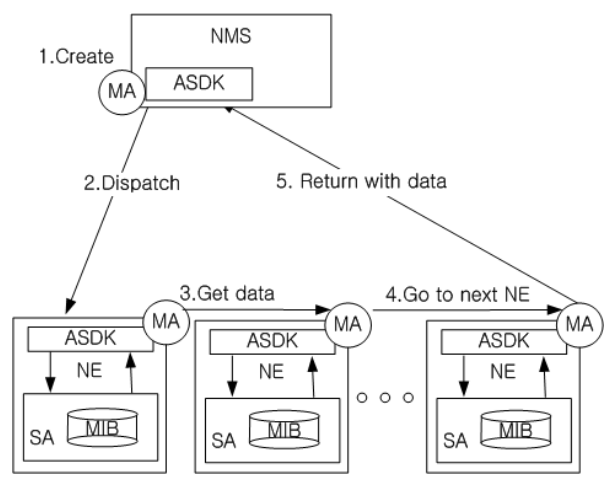

그림 2. $\mathrm{GnG}(\mathrm{Get}$ ' $n$ ' Go)의 동작

Fig. 2. Operation of $\mathrm{GnG}$ (Get ' $n$ ' Go)

$\mathrm{GnG}$ 관리는 네트워크가 여러 서브네트워크로 구성된 환 경에서 유용하며, $\mathrm{NMS}$ 는 각 서브네트워크에 하나의 $\mathrm{MA}$ 를 전송하고 이 MA가 서브네트워크 내의 다른 $\mathrm{NE}$ 들에게 순차 적으로 전송된다. 반면에 $\mathrm{GnS}$ 관리는 $\mathrm{NMS}$ 가 $\mathrm{MA}$ 를 모든 $\mathrm{NE}$ 에게 브로드케스팅한다. $\mathrm{DnD}$ 관리는 $\mathrm{NMS}$ 가 모든 $\mathrm{NE}$ 에게 $\mathrm{MA}$ 를 이동시키고, 이동된 $\mathrm{MA}$ 는 $\mathrm{SA}$ 로부터 정보를 수 집하여 그 결과만NMS에게 메시지로 전송하고 스스로 $\mathrm{NE}$ 로 부터 제거된다.

$\mathrm{MA}$ 기반 네트워크 관리는 유연성과 확장성이 SNMP 기 반의 네트워크 관리보다 우수하다. 하지만 $\mathrm{MA}$ 의 전송에 따른 지연과 보안 문제, 그리고 $\mathrm{MA}$ 플랫폼이 설치된 $\mathrm{NE}$ 로만 이동 및 실행이 가능하다는 단점이 있다. 그러므로 이 관리 구조는 처리 능력과 저장 공간이 충분한 $\mathrm{NE}$, 이기종 $\mathrm{NE}$, 다수의 $\mathrm{NE}$ 가 존재하는 유연성 있는 관리가 필요한 환경에 적합하다.

\section{3 하이브리드 및 기타 네트워크 관리 구조}

$\mathrm{MA}$ 플랫폼이 설치된 $\mathrm{NE}$ 와 설치되지 않은 $\mathrm{NE}$ 가 함께 존재 하는 네트워크는 MA 기반으로 또는 SNMP 기반으로 관리될 수 없다. 이와 같이 다양한 $\mathrm{NE}$ 의 관리를 위해 그림 3 과 같은 하 이브리드 관리 구조가 제안되어 다음과 같이 동작한다[4][5][15].

1) $\mathrm{NMS}$ 는 MA가 전송될 $\mathrm{NE}$ 을 선정한다.

2) 선정된 NE는 MA기반 노드와 SNMP기반 노드를 식 
별하고, $\mathrm{MA}$ 를 전송할 경로를 설정한다

3) 전송 경로에 따라 $\mathrm{NE}$ 에 존재하는 $\mathrm{MA}$ 플랫폼으로 이동 하고 $\mathrm{NE}$ 의 정보를 수집 및 설정한다.

4) $\mathrm{MA}$ 플랫폼이 설치되지 않은 저용량 $\mathrm{NE}$ 는 설정에 따라

$\mathrm{NMS}$ 또는 근거리에 있는 MA가 정보를 수집 및 설정한다. 하이브리드 네트워크 관리는 다양한 이기종 $\mathrm{NE}$ 들을 함께 관리할 수 있는 장점은 있으나 $\mathrm{NE}$ 의 특성을 파악하고, $\mathrm{MA}$ 기반 $\mathrm{NE}$ 들로 이동하기 위한 전송 경로 설정으로 인해 관리의 복잡성이 증가하는 단점이 있다.

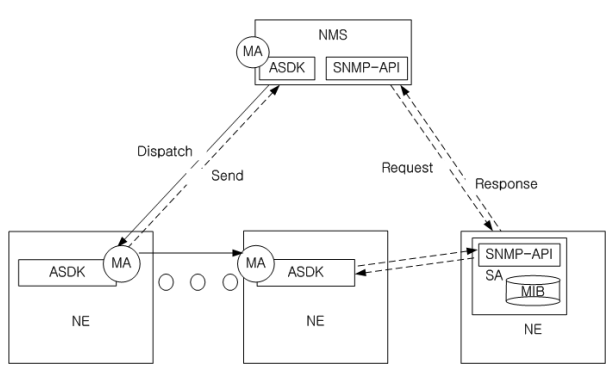

그림 3. 하이브리드 네트워크 관리 구조

Fig. 3. Architecture of hybrid network management

이 외에도, 많은 수의 $\mathrm{NE}$ 들을 효율적으로 관리하기 위해 서브네트워크에 중간 관리 노드를 두어 네트워크를 관리하는 계층적 네트워크 관리 구조와 노드들을 그룹으로 나누고 $\mathrm{MA}$ 에 의해 관리하는 분할 관리 구조도 제안되었다[8][15].

본 장에서 분석한 세 가지 네트워크 관리 구조의 특징들은 표1과 같이 정리될 수 있다.

표 1. 세 가지 네트워크 관리 구조의 비교

Table 1. Comparison of the three network management architectures

\begin{tabular}{|c|c|c|c|}
\hline & SNMP & MA & Hybrid \\
\hline 복잡성 & 단순함 & 복잡함 & 복잡함 \\
\hline 확장성 & ㄴㅏㅃㅃㅁ & 좋음 & 좋음 \\
\hline 지능성 & 나쁨 & 좋음 & 좋음 \\
\hline 구조 & 중앙 집중 & 분산 처리 & 분산처리 \\
\hline 사용 환경 & 소규모 영역 & 대규모 영역 & 이기종 영역 \\
\hline $\mathrm{NE}$ 리소스 & 소규모 & 중규모 이상 & 모두 가능 \\
\hline 장점 & 단순함 & 분산처리 & 혼합 환경 관리 \\
\hline 단점 & $\begin{array}{c}\text { 과부하, } \\
\text { 전송지연 }\end{array}$ & $\begin{array}{c}\mathrm{MA} \text { 플랫폼의 } \\
\text { 설치 }\end{array}$ & 관리의 복잡성 \\
\hline \multicolumn{4}{|r}{} \\
\cline { 2 - 3 }
\end{tabular}

앞에서 분석된 것과 같이 하나의 관리 구조가 모든 네트워크 환경의 관리에 최적일 수 없으며, 각 네트워크 구조들은 동작 특성에 따라 제한된 환경에서 최적의 효율성을 얻을 수 있다.

\section{III. 계층적 네트워크 관리 구조 제안}

\section{1 네트워크 관리 구조의 요구 사항}

본 장에서는 앞장에서 제시한 기존의 다양한 네트워크 관 리 구조들의 분석을 기반으로, 향후 활용이 많을 것으로 기대 되는 네트워크 환경을 효율적으로 관리하기 위한 요구사항을 정의한다.

센서 네트워크, 소규모 이동형 장치 및 소규모 임베디드 장치의 활용이 급증함에 따라, 많은 수의 이와 같은 소규모 $\mathrm{NE}$ 들이 광범위한 영역에 분포되어 있는 네트워크의 효율적 인 관리가 필요해 지고 있다[16][17]. 따라서 본 연구에서는 기존의 다양한 관리 구조의 특성 분석을 기반으로 제시한 네 트워크를 유연성 있게 관리할 수 있는 관리구조의 요구 사항 을 다음과 같이 제시한다.

첫째, 많은 수의 NE들을 중앙 집중적으로 관리하게 되면 $\mathrm{NMS}$ 의 과부하와 네트워크 트래픽의 병목현상이 발생하므 로 중앙 집중적 관리 구조는 피해야한다. 또한 $\mathrm{NE}$ 들이 광범 위한 영역에 분포되어있어 $\mathrm{NMS}$ 와 $\mathrm{NE}$ 들 사이에 네트워크 전송 지연이 발생하므로 이들 사이의 메시지 교환을 최소화 해야 한다.

둘째, $\mathrm{MA}$ 기반의 네트워크 관리 구조는 $\mathrm{MA}$ 플랫폼이 설 치된 환경에서만 $\mathrm{MA}$ 가 이동 및 실행 가능하나, 소규모 $\mathrm{NE}$ 는 처리능력과 저장용량이 작으므로 $\mathrm{MA}$ 기반의 $\mathrm{NE}$ 관리는 피해야 한다.

셋째, 하이브리드 구조에서 $\mathrm{NE}$ 의 유형을 구별하고 $\mathrm{MA}$ 의 경로를 설정하는 처리 과정은 불필요한 과부하를 가져온다. 실제 환경은 동일한 구조의 소규모 $\mathrm{NE}$ 들이 분포되어 있는 경 우가 많으므로 $\mathrm{NE}$ 의 관리는 단순하게 처리해야 한다.

넷째, 향후 네트워크 관리는 다양한 정보의 처리가 요구되 므로, 관리의 유연성을 제공해야하며 관리의 성능(처리 시간) 이 개선되어야 한다.

\subsection{MA+SNMP 기반의 네트워크 관리 구조}

앞 절에 제시한 네트워크 관리 구조의 요구사항을 다음과 같이 만족하는 네트워크 관리 구조를 제안한다.

첫째, 많은 수의 $\mathrm{NE}$ 를 $\mathrm{NMS}$ 의 과부하 없이 처리하려면 $\mathrm{NMS}$ 가 모든 노드들을 관리하는 중앙 집중적 관리가 아닌, 중간 관리 노드를 갖는 계층적 구조로 구성되어야 하며 $\mathrm{NE}$ 들 을 서브네트워크로 분할하여 관리하는 분할 관리구조를 가져 야 한다. 즉, $\mathrm{NMS}$ 의 과부하와 네트워크 트래픽의 병목 현상 을 개선하기 위해 $\mathrm{NMS}$ 의 기능을 중간 관리 노드로 분산시 
키는 구조이며 중간 관리 노드는 과도한 수의 $\mathrm{NE}$ 를 관리하지 않도록 한다. 또한 과도한 네트워크 전송 지연이 발생하는 인 터넷을 통한 메시지 교환을 줄이기 위해 중간 관리 노드가 서 브네트워크 내의 $\mathrm{NE}$ 들만을 관리하도록 한다.

둘째, 관리의 유연성을 위해 중간 관리 노드의 운영은 $\mathrm{MA}$ 기반으로, 소규모 $\mathrm{NE}$ 의 특성을 고려하여 NE는 $\mathrm{SNMP}$ 기반 으로 동작하도록 하는 $\mathrm{MA}+\mathrm{SNMP}$ 기반으로 운영되는 두 계 층의 동작 구조를 갖도록 한다. 두 계층의 운영은 $\mathrm{SNMP}+\mathrm{SNMP}$ 기반과 $\mathrm{MA}+\mathrm{MA}$ 기반도 가능하지만, $\mathrm{SNMP}$ 기반의 운영 $(\mathrm{SNMP}+\mathrm{SNMP})$ 은 단순하고 부하가 분산되는 반면 중간 관리 노드의 프로그램이 수정되면 모두 다시 설치해야 하며 다양한 관리에 대한 유연성이 떨어진다. 그리고 두 계층 모두 를 $\mathrm{MA}$ 기반으로 운영 $(\mathrm{MA}+\mathrm{MA})$ 하게 되면 관리의 유연성은 좋지만 $\mathrm{MA}$ 의 전송에 대한 복잡성이 증가하고 네트워크 과부 하 및 전송 지연이 발생하므로, 이 구조들은 고려하지 않는다.

본 연구에서는 위와 같은 특성을 갖는 $\mathrm{MA}+\mathrm{SNMP}$ 기반 의 네트워크 관리 구조를 그림4와 같이 제안한다.

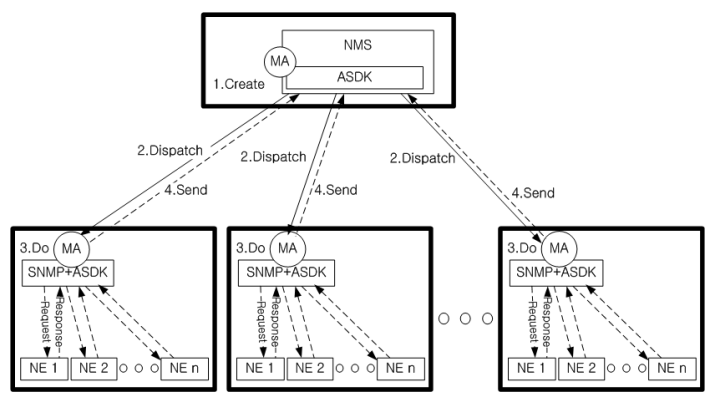

그림 4. MA+SNMP 기반의 네트워크 관리 구조 Fig. 4. Network management architecture based on $\mathrm{MA}+\mathrm{SNMP}$

제안 구조의 동작은 다음과 같다.

1) $\mathrm{NMS}$ 에 존재하는 $\mathrm{ASDK}$ 에서 $\mathrm{MA}$ 인 aglet을 생성한다.

2) 생성된 MA는 각 서브네트워크의 $\mathrm{ASDK}$ 플랫폼이 설 치된 중간 관리 노드로 이동한다.

3) 이동된 MA는 같은 서브네트워크에 존재하는 모든 $\mathrm{NE}$ 의 $\mathrm{SA}$ 와 $\mathrm{SNMP}$ 메시지 교환을 통해 정보를 수집하거 나 설정한다.

4) 각 중간 관리 노드는 수집된 정보를 $\mathrm{NMS}$ 에게 메시지 로 전송한다.

그림4에서 대상 네트워크는 서브네트워크로 분할하여 관리 하며, $\mathrm{NE}$ 의 수, 정보의 요청 수를 고려하여 과부하 없이 제안 관리 구조가 최적의 성능을 내도록 서브네트워크를 분할한다.

각 서브네트워크에는 $\mathrm{NE}$ 의 관리를 위해 하나의 중간 관리
노드가 할당되며, 관리의 유연성과 $\mathrm{NMS}$ 의 부하 경감을 위해 중간 관리 노드는 $\mathrm{MA}$ 기반으로 동작하며 각 $\mathrm{NE}$ 는 $\mathrm{SNMP}$ 기반으로 관리한다.

$\mathrm{NMS}$ 와 각 중간 관리 노드 사이는 네트워크 전송 지연이 발생하고 관리의 유연성이 떨어지는 SNMP 기반으로 동작하 지 않고, 정보의 필터링 등의 유연한 관리가 가능한 $\mathrm{MA}$ 기반 으로 동작한다. 제안 구조에서는 $\mathrm{MA}$ 관리 방법인 $\mathrm{GnG}$, $\mathrm{GnS}$ 및 $\mathrm{DnD}$ 관리 방법을 혼합하여 네트워크 관리에 적합한 동작만을 다음과 같이 적용한다. 즉, 네트워크를 서브네트워 크로 분할하여 서브네트워크 내에 하나의 중간 관리 노드에만 $\mathrm{MA}$ 를 이동하는 방식은 $\mathrm{GnG}$ 관리 기법에서, 중간 관리 노드 로 이동한 MA가 상주하며 정보를 수집하는 방식은 $\mathrm{GnS}$ 관 리 기법에서, 수집된 정보를 $\mathrm{NMS}$ 에게 메시지로 전달하는 방 식은 $\mathrm{DnD}$ 관리 기법에서 채택한다.

구현된 MA는 그림5와 같이 구성된다.

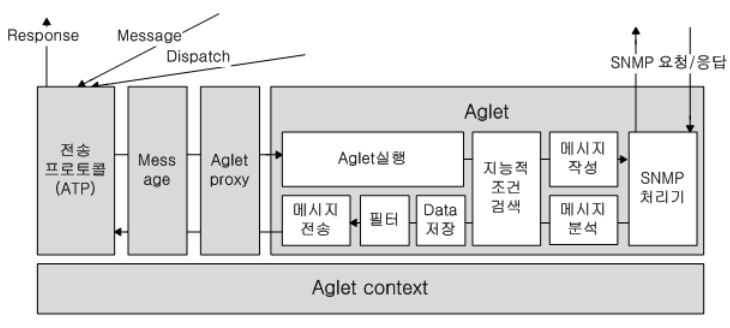

그림 5. 구현된 $\mathrm{MA}$ 의 구성

Fig. 5. Configuration of MA

소규모 $\mathrm{NE}$ 는 처리능력이 낮고 저용량 메모리를 갖는 특성 을 고려하여 SNMP 플랫폼으로 구축하고 중간 관리 노드는 $\mathrm{NE}$ 와 SNMP 메시지 교환을 통해 정보를 수집한다. 중간 관 리 노드는 $\mathrm{NE}$ 들로부터 수집한 모든 정보를 $\mathrm{NMS}$ 에 전송하 지 않고, $\mathrm{NMS}$ 가 필요한 정보만을 $\mathrm{MA}$ 가 지능적으로 필터링 하여 $\mathrm{NMS}$ 에게 메시지로 전송하도록 하여 네트워크를 통한 메시지 크기 또는 전송 횟수를 줄인다.

제안 구조가 서브네트워크로 분할된 분할 구조와 각 서브 네트워크에 $\mathrm{MA}$ 와 $\mathrm{SNMP}$ 기능이 결합된 중간 관리 노드를 할당한 계층적 구조를 채택하여, 네트워크 전송 지연과 $\mathrm{NMS}$ 의 과부하 및 네트워크 관리의 전체 처리 시간에 어떤 영향을 주었는지의 검증은 다음 장에 제시한다.

\section{IV. 검증 및 평가}

제안 구조의 검증과 평가를 위한 시스템 환경은 $\mathrm{NMS}$ 와 $\mathrm{NE}$ 가 모두 하드웨어는 IBM System x3650 M2를, 운영체 
제는 CentOS 5.4 x86_64를, 소프트웨어는 Net-SNMP5 4.2.1, ASDK2.0.2 그리고 jdk1.6.0을, MIB은 IF-MIB 을 사용하였다.

\section{1 중간 관리 노드에 의한 지연 개선 분석}

$\mathrm{NMS}$ 가 $\mathrm{NE}$ 를 관리하기 위해 직접 통신하는 경우와 중간 관 리 노드가 $\mathrm{NE}$ 를 관리하기 위해 통신하는 지연을 비교 분석하기 위해 왕복 지연 시간을 5000 회 측정한 결과는 표 2 와 같다.

표 2. 요청/응답 왕복 지연 시간

Table 2. Request/Response round trip delay time

\begin{tabular}{|c|c|c|c|}
\hline \multirow{2}{*}{ 구간 } & \multicolumn{3}{|c|}{ 왕복 지연 시간(msec) } \\
\cline { 2 - 4 } & 최대 & 최소 & 평균 \\
\hline $\mathrm{NMS}->\mathrm{NE}$ & 509 & 8 & 20 \\
\hline 중간관리노드〈->NE & 1 & 1 & 1 \\
\hline
\end{tabular}

$\mathrm{NMS}$ 와 NE가 직접 통신하는 경우에 네트워크 왕복 지연 시간의 평균은 $20 \mathrm{msec}$ 이고, 중간 관리 노드와 $\mathrm{NE}$ 사이의 통신은 $1 \mathrm{mesc}$ 이하이다. 또한 중간 관리 노드를 사용한 경우 의 왕복 지연 시간은 거의 일정하지만, $\mathrm{NMS}$ 가 직접 관리하 는 경우는 최소 $8 \mathrm{msec}$ 에서 최대 $509 \mathrm{msec}$ 으로 광범위한 영 역에서는 왕복 지연 시간을 보장할 수 없다. 실제로는 중간 관리 노드에서 $\mathrm{NMS}$ 에 필요한 정보만을 필터링을 하여 응답 메시지로 전송하면 메시지 크기나 횟수를 줄일 수 있으므로 광범위한 영역에 많은 수의 $\mathrm{NE}$ 를 관리하기 위해서는 중간 관 리 노드를 갖는 계층적 관리 구조가 적합하다.

\section{2 전송되는 데이터 크기의 분석}

본 절에서는 $\mathrm{NMS}$ 의 과부하 및 네트워크 트래픽의 병목현 상을 분석하기 위해 $\mathrm{NMS}$ 에서 송수신되는 메시지의 크기와 인터넷을 통한 메시지 전송 회수를 비교한다.

$\mathrm{SNMP}$ 요청과 응답 그리고 MA가 1회 이동할 때의 메시 지 전송회수와 메시지 크기는 표3과 같다. 표3에 제시된 메시 지 크기는 제어 메시지까지 포함한 크기이다.

표 3. SNMP와 MA의 메시지 비교

Table 3. Comparison of SNMP and MA message

\begin{tabular}{|c|c|c|c|}
\hline & $\begin{array}{c}\text { 메시지 평균 } \\
\text { 크기(byte) }\end{array}$ & $\begin{array}{c}\text { 메시지 전송 } \\
\text { 횟수 }\end{array}$ & 전송 계층 \\
\hline $\begin{array}{c}\text { SNMP } \\
\text { 요청/응답 }\end{array}$ & 요청 : 88 & 1 & \multirow{2}{*}{ UDP } \\
\cline { 1 - 3 } $\begin{array}{c}\mathrm{MA} \text { 의 } \\
\text { 이동/메시지 }\end{array}$ & 응답 : 90 & 1 & \\
\cline { 2 - 3 } & 이몽옹과메시지 : 754 & 17 & \multirow{2}{*}{$\mathrm{TCP}$} \\
\hline
\end{tabular}

각 $\mathrm{NE}$ 의 정보 요청 수는 5 로 설정하고, 각 서브네트워크 내의 $\mathrm{NE}$ 수는 40 으로 설정하고, 전체 $\mathrm{NE}$ 의 수는 200 에서 1000 까지 증가하며 네트워크 관리를 위해 NMS에서 송수신 되는 메시지의 크기를 측정한 결과는 그림6과 같다.

비교 기법은 전통적인 SNMP 기반, 본 연구에서 제안한 $\mathrm{MA}+\mathrm{SNMP}$ 기반 그리고 $\mathrm{MA}$ 기반 기법이다. $\mathrm{MA}$ 기반은 서브네트워크로 분할하는 경우(그림에서 $\mathrm{MA}+$ Partition로 표시)와 분할하지 않은 경우 (MA로 표시) 로 나누어 실험하 였다. MA 기반과 $\mathrm{MA}+\mathrm{SNMP}$ 기반은 서브네트워크의 증가 에 따라 송수신 데이터 크기가 증가하고, $\mathrm{SNMP}$ 기반은 정보 요청수와 $\mathrm{NE}$ 의 수에 따라 데이터 크기가 증가한다. 표3에서 보이듯이 MA의 메시지 평균 크기가 SNMP 메시지보다 크지 만, $\mathrm{NMS}$ 에서 SNMP의 요청/응답 메시지가 많기 때문에 $\mathrm{NMS}$ 에 전송되는 데이터의 크기는 $\mathrm{SNMP}$ 기반이 가장 크다.

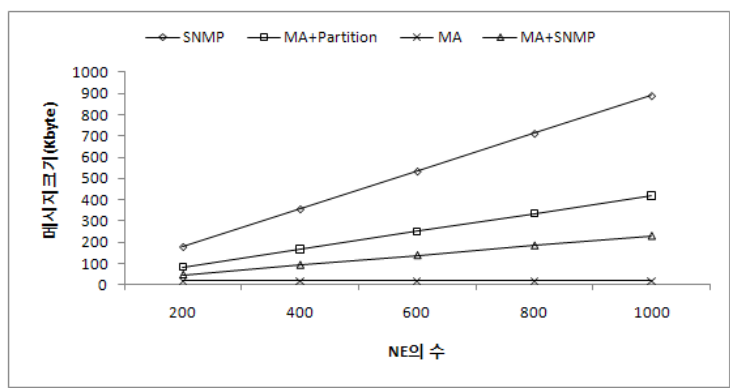

그림 6. NMS에서 송수신되는 메시지의 크기

Fig. 6. Size of message from/to NMS

네트워크 관리를 위해 NMS의 메시지 송수신 회수를 측정 한 결과는 그림7과 같다.

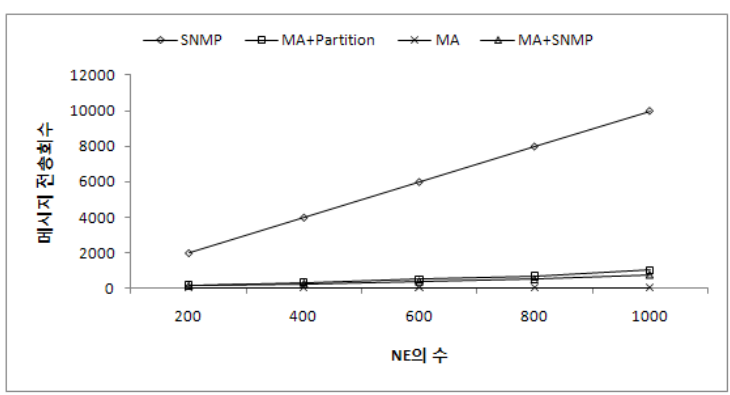

그림 7. $\mathrm{NMS}$ 의 메시지 전송 회수

Fig. 7. Number of messages exchanged through NMS

그림6과 그림7을 통해, 본 연구에서 제안한 $\mathrm{MA}+\mathrm{SNMP}$ 가 $\mathrm{NMS}$ 의 과부하 측면과 인터넷을 통한 메시지 전송 측면에 
서 개선됨을 알 수 있다.

\section{3 소규모 NE의 지원 분석}

$\mathrm{SNMP}$ 기반 네트워크 관리를 위해서는 $\mathrm{NE}$ 에 $\mathrm{SA}$ 만 설치 되고 $\mathrm{MA}$ 기반 네트워크 관리를 위해서는 자바 가상머신 (Java $\mathrm{VM}$ ), $\mathrm{ASDK}$, 그리고 MA가 설치되어야 하며, 필요 한 메모리 용량은 표4와 같다[12].

\section{표 4. $\mathrm{MA}$ 플랫폼과 $\mathrm{SA}$ 의 메모리 공간}

Table 4. Memory space usage of SA and MA platform

\begin{tabular}{|c|c|c|}
\hline \multicolumn{2}{|c|}{ NE에 설치된 S/W } & 메모리 사용 크기 \\
\hline $\begin{array}{c}\text { SNMP } \\
\text { 기반 }\end{array}$ & $\mathrm{SA}$ & 수십Kbyte 내외 \\
\hline \multirow{3}{*}{$\begin{array}{c}\text { MA } \\
\text { 기반 }\end{array}$} & Java VM & 수십Mbyte 내외 \\
\cline { 2 - 3 } & ASDK & 수Mbyte \\
\cline { 2 - 3 } & MA & 수Kbyte 내외 \\
\hline
\end{tabular}

소규모 이동형 장치 및 소규모 임베디드 장치와 같은 $\mathrm{NE}$ 는 저용량의 메모리를 갖는다. 그러나 표4에서 $\mathrm{MA}$ 기반은 상당한 크기의 메모리를 요구하므로, MA플랫폼을 소규모 $\mathrm{NE}$ 에 설치하는 것은 무리가 될 수 있다. 따라서 소규모 $\mathrm{NE}$ 들을 관리하기 위해서는 MA 기반 구조보다 SNMP 기반 구 조가 적합하다.

\section{4 처리 시간의 비교 분석}

성능의 비교 평가를 위해 $\mathrm{NMS}$ 가 정보를 요청하고 $\mathrm{NE}$ 들 로부터 정보를 수신 완료까지의 시간인 전체 처리 시간을 $\mathrm{SNMP}$ 기반, 두 가지 MA 기반 그리고 MA+SNMP 기반 기법에 대해 비교 분석한다. 설정은 4.2 절과 동일하다.

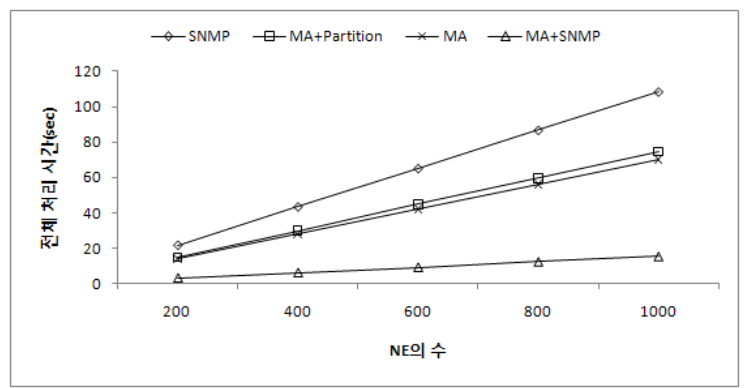

그림 8. SNMP-Set에 대한 전체 처리 시간 비교

Fig. 8. Total processing time for SNMP-Set

그림8은 SNMP-Set을 실행한 결과이다. SNMP 기반은 인 터넷을 통한 전송이 $\mathrm{NE}$ 당 정보 요청수와 $\mathrm{NE}$ 의 수에 따라 전체
처리 시간이 증가하기 때문에 가장 비효율적이다. 그리고 그림6 과 그림7에서 $\mathrm{MA}$ 기반이 $\mathrm{MA}+\mathrm{SNMP}$ 기반보다 $\mathrm{NMS}$ 에서 송 수신되는 메시지의 크기나 인터넷을 통한 메시지 전송 회수 측면 에서 우수하지만, $\mathrm{MA}$ 기반은 서브네트워크 내의 모든 NE로 표 3 과 같이 커다란 MA가 메시지를 분할하여 전송되기 때문에 작 은 크기의 요청/응답 메시지만 전송하는 $\mathrm{MA}+\mathrm{SNMP}$ 기반이 전체 처리 시간 측면에서 우수함을 보인다.

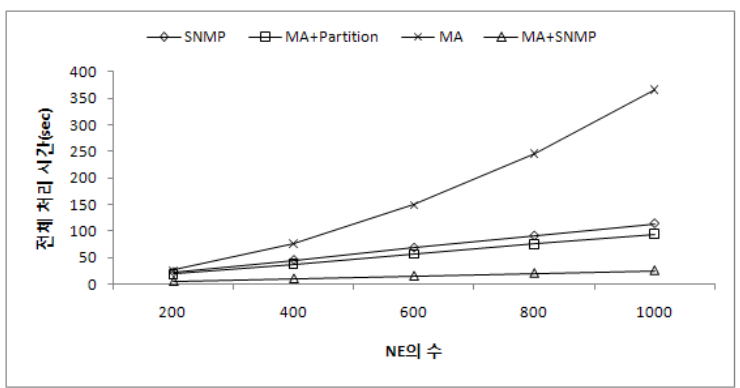

그림 9. SNMP-GetBulk에 대한 전체 처리 시간 비교

Fig. 9. Total processing time for SNMP-GetBulk

그림9는 Max-repetition을 10으로 SNMP-GetBulk을 실행한 결과이다. SNMP기반, $\mathrm{MA}+$ Partition기반 그리고 $\mathrm{MA}+\mathrm{SNMP}$ 기반은 SNMP-Set과 유사하게 SA로부터 10 개의 값을 읽어 오는 시간과 읽어온 데이터를 전송하는 시간 에 비례해서 전체 처리시간이 증가하지만, MA기반은 데이터 를 계속 누적해서 MA가 이동하기 때문에 전체 처리 시간 측 면에서 가장 비효율적이다.

즉, 서브네트워크와 $\mathrm{NE}$ 의 개수를 증가시켜 광범위한 영역 에 많은 수의 소규모 $\mathrm{NE}$ 가 분포된 환경에서 분석한 결과, 제 안 구조의 전체 처리 시간이 기존 네트워크 구조보다 우수함 을 보인다.

\section{V. 결 론}

다양해지고 복잡해지는 네트워크를 효율적으로 관리하기 위 해 $\mathrm{SNMP}$ 기반의 중앙 집중적인 관리 구조, $\mathrm{MA}$ 기반의 분산 관리 구조, 그리고 하이브리드 네트워크 관리 구조가 출연하였 지만 하나의 관리 구조가 모든 네트워크 환경에서 최적일 수는 없고 각 네트워크의 동작 특성에 따라 제한된 환경에서 최적의 효율성을 보인다.

본 연구에서는 향후 활용이 급증할 것으로 예상되는 많은 수 의 소규모 $\mathrm{NE}$ 들이 광범위한 영역에 분포되어 있는 환경에서 네 트워크를 효율적이며 유연성 있게 관리할 수 있는 $\mathrm{MA}+\mathrm{SNMP}$ 
기반의 계층적 네트워크 관리 구조를 제안 하였다.

즉, 제안구조는 $\mathrm{NMS}$ 의 과부하와 네트워크 트래픽의 병목 현상을 개선하기 위해 $\mathrm{NMS}$ 의 기능을 중간 관리 노드로 분 산 시키는 계층적 구조이며 중간 관리 노드는 서브네트워크마 다 지정되는 분할 구조이다.

관리의 유연성을 위해 중간 관리 노드의 운영은 $\mathrm{MA}$ 기반 으로, 소규모 $\mathrm{NE}$ 의 특성을 고려하여 $\mathrm{NE}$ 는 $\mathrm{SNMP}$ 기반으로 동작하도록 하는 $\mathrm{MA}$ 와 $\mathrm{SNMP}$ 로 운영되는 두 계층의 동작 구조를 갖도록 하였다.

측정과 분석을 통해 제시된 환경에서 제안 구조는 기존 관 리 구조의 취약점인 NMS의 과부하, 네트워크 트래픽 및 $\mathrm{MA}$ 플랫폼 설치의 과부하 문제를 개선하여 전체 처리 시간이 개 선됨을 보였다.

본 연구의 제안에 의해 광범위한 영역에 분포된 센서 네트 워크, 소규모 이동형 장치 및 소규모 임베디드 장비로 구성된 네트워크를 효율적으로 관리할 수 있을 것이다.

제안 관리 구조의 광범위한 분석을 위해서, 본 연구에서는 실시하지 못한 소규모 $\mathrm{NE}$ 들이 적용된 다양한 실제 환경에서 의 성능 분석이 향후 연구로 요구된다.

실제 네트워크 관리의 적용 환경이 다양해짐에 따라 기존 의 SNMP 기반 관리 구조, $\mathrm{MA}$ 기반의 관리 구조와 본 연구 에서 제안한 $\mathrm{MA}+\mathrm{SNMP}$ 기반의 관리 구조와 같이 다양한 네트워크 관리 구조를 통합하여 관리할 수 있는 방법이 필요 할 것으로 분석되어 향후 연구 과제로 추진하고 있다.

\section{참고문헌}

〔1] 나호진, 조경산, "네트워크 관리 프로토콜 SNMP의 성능 항상," 한국검퓨터정보학회논문지, 제 15권, 제 2호, 99-107쪽, 2010년 2월.

[2] 강경인, 박경배, "이동 애드 혹 네트워크에서의 트래픽 관 리," 한국컴퓨터정보학회논문지, 제 14권, 제 9호, 29-35쪽, 2009년 9월.

[3] A. Holt, C. Huang and J. Monk "Performance analysis of mobile agents," IET, Vol. 1, pp. 532-538, 2007.

[4] M. Nair, C. Bhosle, V. Gopalakrishna, "Net Mobile-Cop: A hybrid intelli-agent framework to manage networks," Procs. of IAMA 2009, pp. 1-8, 2009.

[5] B. Olutayo, D. Akinde, and T. Akinwale, "Framework on Hybrid Network Management System Using a Secure Mobile Agent Protocol," Procs. of IISIT
2009, Vol. 6, pp. 617-629, 2009

[6] William Stalling, "SNMP, SNMPv2, SNMPv3, RMON 1 and 2 Third Edition," Addison Wesley, 1996.

[7] Z. Hong-fang, G. Feng, Y. Zeng-qiang and W. Guang-xing, "Research on mobile agent-based hierarchical network management model," Procs. of MAPE 2005, Vol. 2, pp.1571-1575, 2005.

[8] 이재형, 오길호, "분할관리정책에 의한 이동 에이전트를 이용한 효율적인 네트워크 관리," 한국콘텐츠학회논문지, 제 7권, 제 8호, 66-75쪽, 2007년 8월.

[9] M. Kona, X. Cheng-Zhong, "A Framework for Network Management using Mobile Agents," Procs. of IPDPS 2002, pp. 227-234, 2002.

〔10] Z. Gu-ping, D. Wen-bo "The research of mobile agent-based distributed network management," Procs. of CCCM 2009, Vol. 1, pp. 182-185, 2009.

〔11〕 L. Ma, J. Tsai, "Formal Modeling and analysis of a secure mobile-agent system," Systems, Man and Cybernetics, Part A, IEEE Transaction, Vol. 38, No 1, pp. 180-196, 2008.

[12] Aglets Project, http://www.trl.ibm.com/aglets/

〔13] O. Abdelkader, "Mobile-Agent-based Application : a Survey," IJCSNS, Vol. 9, №. 11, pp. 331-339, 2009.

〔14] D. Gavalas, D. Greenwood, M. Ghanbari, M. O'Mahony, “Advanced Network Monitoring Applications Based on Mobile/Intelligent Agent Technology," Computer Communications Journal, Vol. 23, No. 8, pp.720-730, 2000.

〔15] P. Saravanan, E. Reuter, S. Verma, "Enhancing Enterprise Network Management using SMART," Procs. of INDICON 2008, Vol. 2, pp. $343-348,2008$.

〔16] K. Yong-Woon, L. Jun-Seob, Y. Sang-Keun and K. Hyoung-Jun, "An ID-based USN Management Architecture Model," Procs. of ACT 2007, Vol. 1, pp. 251-254, 2007.

〔17〕 곽득휘, 이현룡, 김종원, "SNMP 기반의 이동형 네트워 크 장비 관리 기법,” 한국통신학회논문지, 제 33 권, 제 7호, 557-566쪽, 2008년 7월. 


\section{저 자 소 개}

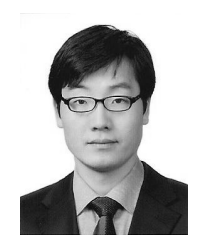

나 호 진

1998 : 단국대학교 응용물리학과(학사)

2001 : 단국대학교 전산통계학과(이

학석사)

2006년 3월 현재 :

단국대학교 컴퓨터과학(박사과정)

관심분야 : 네트워크 관리, 지능형 에

이젠트, 네트워크 통신,

임베디드 컴퓨팅

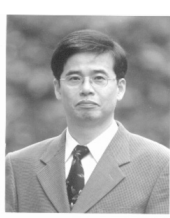

조 경 산

1979 : 서울대학교 전자공학과(학사)

1981 : 한국과학원 전기전자공학과 (공학석사)

1988 : 텍사스 대학원(오스틴) 전기 전산공학과(Ph.D.)

1988 1990 : 삼성전자 컴퓨터부문 책임연구원, 실장

1990 현재 : 단국대학교 컴퓨터학부 교수

관심분야 : 네트워크시스템 및 이동통 신보안, 컴퓨터시스템 